\title{
PERFIL DOS TRABALHADORES DE ENFERMAGEM NO PROGRAMA DE SAÚDE DA FAMÍLIA ${ }^{1}$
}

\author{
THE PROFILE OF NURSING PERSONNEL IN THE FAMILY HEALTH \\ PROGRAM \\ PERFIL DE LOS TRABAJADORES DE ENFERMERÍA EN EL PROGRAMA \\ DE SALUD DE LA FAMILIA
}

Rafaela Azenha Teixeira²

Silvana Martins Mishima ${ }^{3}$

\begin{abstract}
RESUMO: O estudo objetiva caracterizar a configuração demográfica dos trabalhadores ligados à enfermagem de equipes do PSF de 3 municípios de São Paulo e analisar a percepção destes quanto ao perfil profissional necessário à atuação junto ao PSF. Utilizou-se como instrumento para coleta de dados a entrevista semi-estruturada. Para a sistematização inicial dos dados utilizou-se do software ETHNOGRAPH, e, posteriormente realizou-se análise temática. Os temas identificados na fala dos trabalhadores, apontam para um "perfil necessário" à atuação no PSF: há uma percepção de que os trabalhadores devem ser comunicativos, dedicados, envolvidos, solidários, carinhosos, ter bom relacionamento, disponibilidade e ajudar a população. O conjunto dos dados, embora aponte em alguns momentos para um perfil profissional que contemple uma prática de caráter assistencialista, ao mesmo tempo encaminha para uma reflexão acerca de uma nova configuração da prática assistencial alicerçada na humanização e integralidade da assistência, assim como na construção da cidadania.
\end{abstract}

PALAVRAS-CHAVE: saúde da família, enfermagem em saúde pública, recursos humanos em enfermagem

\section{INTRODUÇÃO}

A questão dos recursos humanos ${ }^{4}$ na área da saúde vem sendo colocada como um dos pontos nevrálgicos para a construção de um sistema de saúde (Campos, 1989) que se paute pelo respeito aos princípios e diretrizes presentes na proposta de consolidação do Sistema Único de Saúde - SUS. Ao olharmos para esta questão, especificamente na saúde pública, devemos considerar a história sanitária contemporânea, com as intensas transformações pelas quais o setor tem passado. Com a implantação e o movimento de consolidação do SUS desafios são colocados para a adequação dos trabalhadores de saúde aos seus princípios.

1 Projeto financiado pelo CNPq -520347/98-6 - "A organização do trabalho em atenção primária à saúde - uma perspectiva para o trabalho de enfermagem". Prêmio Izaura Barbosa Lima. $1^{\circ}$ lugar, $52^{\circ} \mathrm{CBEn}$.

${ }^{2}$ Enfermeira e aluna do Curso de Pós-graduação em Enfermagem de Saúde Pública - nível Mestrado do Departamento de Enfermagem Materno Infantil e Saúde Pública da Escola de Enfermagem de Ribeirão Preto - USP - rafazenha@ig.com.br

${ }^{3}$ Enfermeira, Professora Doutora junto ao Departamento de Enfermagem Materno Infantil e Saúde Pública da Escola de Enfermagem de Ribeirão Preto - USP - smishima@eerp.usp.br.

${ }^{4}$ Aqui não estaremos optando pela terminologia recursos humanos e sim trabalhadores de saúde, uma vez que estamos tomando estes em suas relações mais gerais no desenvolvimento do trabalho em saúde. 
Em seu estudo, Corneta (1996) coloca que se deve considerar 3 pontos fundamentais para as discussões e reflexões sobre os trabalhadores em saúde, sendo eles: conceito de saúde, a realidade sanitária e a conformação do processo de acompanhamento e avaliação da produção de serviços. Estes pontos são considerados fundamentais, pois afirma que a partir da forma como conceituamos e compreendemos a saúde serão organizadas as práticas de saúde e desenvolvidas as suas ações, definindo-se assim o perfil do profissional que irá atuar neste contexto.Ainda, coloca que a realidade sanitária e os processos de acompanhamento e avaliação da produção de serviços são instrumentos utilizados para dimensionar tanto ações como quais trabalhadores irão compor as diferentes equipes, de acordo com as necessidades da população a serem enfrentadas.

Ao considerarmos a saúde de uma forma ampliada e integral e a complexidade do processo saúde-doença, verificamos a necessidade de um trabalhador com um perfil que corresponda às demandas identificadas na população, com uma atuação que leve em, conta as dimensões sociais, econômicas, subjetivas e biológicas dos usuários.

O Programa de Saúde da Família - PSF, enquanto estratégia de reversão de modelo assistencial de saúde, possibilita pensarmos numa nova forma de organização das práticas de saúde, pois traz uma compreensão ampliada do conceito de saúde, colocando a família como ponto central da atenção e entendendo-a a partir do ambiente em que vive. Desta forma, tornase necessária a definição de novos perfis profissionais para atuação nesta "nova" realidade sanitária. O PSF funciona com equipes multiprofissionais, sendo considerada a equipe mínima de trabalho: 1 médico, 1 enfermeira, 2 auxiliares de enfermagem e de 4 a 6 agentes comunitários de saúde, podendo outros profissionais serem inseridos.

Apesar de todos os trabalhadores de saúde possuírem os seus núcleos específicos de atuação e conhecimento, é esperado que todos tenham como campo de atuação a abordagem de aspectos subjetivos e sociais na sua prática assistencial ${ }^{5}$.

\section{OBJETIVOS}

Considerando o quadro traçado, esta investigação tem por objetivos:

- Caracterizar a configuração demográfica dos trabalhadores ligados à enfermagem que compõem as equipes que atuam no Programa de Saúde da Família na região da DIR XVIII.

- Analisar a percepção dos trabalhadores ligados à enfermagem quanto ao perfil necessário à atuação no Programa de Saúde da Família no conjunto dos municípios da DIR XVIII.

\section{PERCURSO METODOLÓGICO}

O estudo realizado é de natureza exploratória e descritiva, onde o cenário do estudo foi constituído pelos municípios vinculados à DIR XVIII, no Estado de São Paulo, que em janeiro de 1999, dispunham de equipes do PSF.

PROCEDIMENTOS METODOLÓGICOS

\section{A escolha do campo de estudo e a coleta dos dados}

${ }^{5}$ Campos (1997) define como núcleo de competência o conjunto de saberes e responsabilidades específicas a cada profissão ou especialidade. O núcleo marca a diferença entre os membros de uma equipe. Por campo ter-se-iam saberes e responsabilidades comuns ou confluentes a várias profissões, como noções genéricas sobre políticas, processo saúde-doença, organização de modelos e do processo de trabalho em saúde. 
Dentro da Divisão Regional da Saúde XVIII - DIR XVIII do Estado de São Paulo, tinha-se até Dezembro de 1998, dos 25 municípios que a compunham, 3 que vinham desenvolvendo o PSF.

A caracterização geral destes municípios foi realizada através de dados secundários obtidos junto à DIR XVIII. Ainda para o desenvolvimento da pesquisa e obtenção de dados adicionais, foi encaminhado aos Secretários Municipais de Saúde de cada município o resumo do projeto solicitando a autorização para a realização da pesquisa, sendo que obtivemos total disponibilidade para a mesma.

A seguir, numa primeira aproximação com cada município, foram obtidas informações adicionais acerca da caracterização geral do município através de dados fornecidos pelo Departamento de Saúde dos municípios selecionados utilizando para tanto um roteiro, onde constam aspectos gerais quanto à população, dados sócio- econômicos e organização de rede de serviços municipais.

Num segundo momento, buscou-se obter a caracterização geral dos trabalhadores do PSF onde utilizamos um roteiro, constando aspectos demográficos, formação e experiência anterior na área da saúde e em Atenção Primária à Saúde - APS e sua percepção quanto ao programa, sendo que o instrumento selecionado para esta fase foi a entrevista semi-estruturada.

A coleta de dados foi realizada de fevereiro à agosto de 1999. É importante salientarmos que o projeto foi encaminhado ao Comitê de Ética em Pesquisa da EERP - USP, que após análise autorizou a sua realização.

Os entrevistados foram os trabalhadores de enfermagem e agentes comunitários de saúde que atuavam no PSF dos municípios selecionados.

\section{Construção da análise dos dados}

Para a etapa de análise dos dados, utilizamos "Análise Temática", que segundo Minayo (1998), "[...] consiste em descobrir os núcleos de sentido que compõem uma comunicação cuja presença ou freqüência signifiquem alguma coisa para o objetivo analítico visado".

\section{APRESENTANDO E ANALISANDO OS DADOS}

\section{CARACTERIZANDO OS CENÁRIOS DE TRABALHO DO PSF - A APRESENTAÇÃO DOS TREAS MUNICÍPIOS}

Os três municípios, foco deste estudo, situam-se no estado de São Paulo, na área de abrangência da Micro Região II e IV, sob coordenação da Divisão Regional de Saúde de Ribeirão Preto- DIR XVIII, distando em média 50 km de Ribeirão Preto. Todos os três municípios encontramse em gestão plena ${ }^{6}$ do sistema municipal de saúde.

OPSF, no estado de São Paulo, de modo geral, apresenta-se como um processo recente e os municípios integrantes deste estudo contavam com 7 meses de implantação do programa por ocasião da coleta de dados( dezembro de 1998).

Segundo dados do Ministério da Saúde ${ }^{7}$, em 1994, apenas 55 municípios brasileiros possuíam o PSF implantado totalizando 382 equipes. Em junho de 2000, este número é de 2.438 municípios, com um total de 7.291 equipes atuando. A Tabela 1 mostra que é na região

\footnotetext{
${ }^{6}$ Segundo o Manual de Atenção Básica do Ministério da Saúde entende-se por gestão plena do sistema municipal de saúde a responsabilidade integral do município por seu sistema de saúde local.

${ }^{7}$ Pesquisa realizada no site www. saude.gov.br/psf/programa/index.asp em 17 de maio de 2000
} 
Nordeste do país que se concentra a maior parte da equipes e dos programas existentes no Brasil. Apesar dos números da região sudeste ficarem pouco atrás devemos salientar que $50,51 \%$ das equipes desta região estão concentradas no Estado de Minas Gerais. O Estado de São Paulo possui 645 municípios, sendo que 239 destes possuem o programa implantado representando $37,05 \%$ de cobertura do programa, com 676 equipes.

TABELA 1 - Distribuição numérica e percentual dos municípios que possuem PSF implantado assim como o número de equipes de PSF por região do país em abril de 2000. Ribeirão Preto, 2000.

\begin{tabular}{c|c|c|c|c}
\hline \multirow{2}{*}{ Regiōes } & \multirow{2}{*}{ Municípios } & \multicolumn{2}{|c|}{ Municípios com PSF } & \multirow{2}{*}{ Equipes de PSF } \\
\cline { 3 - 4 } & & $\mathbf{n}^{\mathbf{0}}$ & $\mathbf{\%}$ & \\
\hline Norte & 449 & 252 & 30.03 & 560 \\
\hline Nordeste & 1.787 & 862 & 48.24 & 2.972 \\
\hline Centro Oeste & 446 & 140 & 31.39 & 615 \\
\hline Sudeste & 1.666 & 836 & 50.18 & 2.245 \\
\hline Sul & 1159 & 348 & 30.03 & 899 \\
\hline Brasil & 5.507 & 2.438 & 30.03 & 7.259 \\
\hline
\end{tabular}

Fonte: Consulta realizada no site (www.saude.gov.br/psf/programa/index.asp.) em junho de 2000. Dados referentes à abril de 2000

\section{Município A}

Este município possuía uma população, segundo dados do Plano Diretor da Saúde para o município (1998) de 48.934 habitantes com estimativa de que $44.530(91 \%)$ residiam na zona urbana e 4.404 (9\%) na zona rural. Quanto à distribuição da população, por faixa etária $56,1 \%$ são jovens com até 29 anos e que $9,6 \%$ enquadravam-se na faixa etária de indivíduos com mais de 60 anos.

Existiam disponiveis na rede municipal 6 unidades de saúde pública, o Asilo dos Pobres, Serviço Auxiliar Diagnóstico de Terapia, APAE e o Hospital Santa Casa de Misericórdia que atendia através do SUS e de convênio. Este hospital possuía 104 leitos, com 90 para o atendimento de pacientes do SUS e 14 para paciente particular.

OPSF deste município começou a funcionar em junho de 1998, sendo que sua sede de atendimento está localizada na área industrial da cidade, próximo a periferia e a microárea onde é prestada assistência de saúde à população.

\section{Município B}

Segundo dados obtidos do SEADE em 1996, a população era de 21.586 habitantes. Levantamento realizado pela Prefeitura Municipal, para 1998, estimou a população em 30.000 habitantes, sendo $36,3 \%$ entre 0 - 14 anos, $47,2 \%$ entre 15 e 49 anos e $16,5 \%$ acima de 50 anos.

Seu sistema de saúde era composto por 3 unidades básicas de saúde, 1 hospital filantrópico, 1 ambulatório de saúde mental, 1 clínica odontológica e 1 consultório de fonoaudiologia.

O PSF começou a funcionar neste município em agosto de 1998, localizando-se em uma UBS próxima a microárea a qual presta assistência. Anterior à implantação do PSF no município, havia outro programa semelhante, com uma equipe que prestava assistência à comunidade, com a existência de cadastro das famílias e a formulação do diagnóstico da 
comunidade. Este programa foi adequado aos moldes das exigências do Ministério da Saúde e então substituído pelo atual PSF. Dentre outras modificações propostas para contemplar as exigências do Ministério da Saúde, foram alterados os prontuários familiares e adequou-se a equipe com contratação de enfermeira.

\section{Município C}

Este município possuía uma população, segundo dados do Plano Diretor de Saúde para o município (1997) projetada de 22.827 habitantes, sendo esta $66 \%$ maior de 15 anos e apenas $3,21 \%$ menor de 1 ano. Este município possuía a peculiaridade de abastecer de mão de obra as usinas de açúcar e álcool e os canaviais que ficam próximos ao município. Sendo esta uma atividade sazonal, a cidade ainda sofre grandes dificuldades de planejamento de seus equipamentos sociais, quer pelo número elevado de imigrantes, refletindo em uma significativa população flutuante, quer pelo número elevado de desempregados na entre-safra.

Existiam disponíveis na rede municipal 3 unidades básicas, 1 centro odontológico, 1 ambulatório de saúde mental, 1 clínica de fisioterapia e reabilitação e 1 hospital e maternidade que possui 52 leitos, sendo destes 35 para o atendimento do SUS e 17 particular.

O PSF começou a funcionar no município em julho de 1998 e está localizado em uma UBS próximo à microárea a qual presta assistência, apresentando integração com os demais equipamentos sociais disponíveis no município como aqueles ligados à assistência social e com o nivel terciário.

\section{AS EQUIPES DE TRABALHO DO PSF - CARACTERIZAÇÃO DEMOGRÁFICA E O “PERFIL NECESSÁRIO"8}

Conforme podemos constatar o Município A é o que possui equipe "mais completa", ao consideramos que além da equipe mínima preconizada pelo Ministério da Saúde, o dentista também a compõe, realizando prioritariamente atividades preventivas e curativas no grupo infantil.

Os Municípios B e C são compostos pelo mesmo número de trabalhadores possuindo apenas 1 auxiliar de enfermagem. Todos os municípios possuíam a equipe mínima conforme preconizado pelo Ministério da Saúde (BRASIL, 1998): "É recomendável que a equipe de uma unidade de Saúde Família seja composta, no mínimo por um médico de família ou generalista, enfermeiro, auxiliar de enfermagem e agentes comunitários de saúde (ACS). Outros profissionais poderão ser incorporados a estas unidades, d acordo com as demandas e características de organização dos serviços locais de saúde."

Apesar de fazerem parte da equipe, 2 dos enfermeiros, nos Municípios A e B, não possuíam dedicação exclusiva no PSF, desenvolvendo outras atividades na rede básica e na Secretaria Municipal da Saúde, o que "parece" refletir na forma como a equipe é coordenada e o trabalho desenvolvido. Na ausência do enfermeiro em tempo integral no programa, os auxiliares de enfermagem e os ACS recorrem aos médicos e o trabalho do enfermeiro fica restrito a uma supervisão mais distante, como podemos verificar nas falas.

[...] a gente tem mais argumentos para convencer que aquilo não é um procedimento correto, que o mal de 7 dias, não é mal de 7 dias, que é importante a vacinação. Então, eu acho que é muito importante neste ponto, que a gente tem mais argumentos, menos que a Doutora X, neste caso, né. (Auxiliar de Enfermagem 3)

${ }^{8}$ Levantamento de dados correspondente ao período janeiro a dezembro de 1999. 
[...] as ACS passam para a Doutora X, né ... para ver qual o procedimento correto, aí se tem algum curativo, ou injeção diária, igual tinha um aqui que estava tomando medicação para [...] (Auxiliar de Enfermagem 3)

Nestes casos, o planejamento das atividades e de alguns cuidados específicos de enfermagem é realizado pelo médico do programa, enquanto que no Município $A$ o enfermeiro fica mais próximo da equipe possibilitando maior apoio, orientação, capacitando a equipe sempre que necessário e planejando junto com a equipe os cuidados de enfermagem a serem realizados, como podemos verificar nas falas que se seguem.

[...] mas dependendo do problema ou da doença a gente vem para cá, a ENF1 vai lá, ou a ENF1 ou os auxiliares de enfermagem, então fica mais fácil, mais tranqüilo [...] (Agente Comunitário de Saúde 1)

Tem alguns casos que assustam a gente, entendeu, que ai a ENF1 deu um apoio tremendo para a gente, porque ela é mais experiente, então a gente corre para ela quando acontece alguma coisa e têm casos assim mais complicados, sabe. E aí a gente corre para a ENF1 para ela dar uma ajuda... (Agente Comunitário de Saúde 3)

[...] eu vou, os agentes, [...], identificam o problema, passam para a ENF1 que é a enfermeira e coordenadora ela vai, faz a avaliação do caso e passa e aí ela faz a supervisão, vê se tem que internar, vê o grau que é o curativo que está sendo feito [...] (Auxiliar de Enfermagem 2)

O enfermeiro que está mais próximo passa a ser o referencial da equipe sendo solicitado em casos mais complicados e seu trabalho valorizado pela equipe.

Quanto à caracterização dos trabalhadores do PSF, ligados (direta ou indiretamente) a área de enfermagem dos 3 municípios, esta consta de aspectos demográficos, formação e experiência anterior na área da saúde e na área de Atenção Primária à Saúde ${ }^{9}$.

\section{Caracterização demográfica dos trabalhadores ligados direta ou indiretamente à equipe de enfermagem}

Do conjunto de 19 trabalhadores ligados direta ou indiretamente à área de enfermagem ${ }^{10}$, foram entrevistados 16, sendo que apenas no Município C, não foi possível o contato com todos os trabalhadores ligados direta ou indiretamente ligados à área de enfermagem.

De acordo com o levantamento foi possível observar que a faixa etária dos 30-35 anos é a que concentra maior número de trabalhadores $(31,2 \%)$, seguida pela faixa dos $35-40$ anos (25\%). Contudo, ao considerarmos em conjunto as faixas etárias entre 20-25 e 25-30 anos, estas representam $31,25 \%$ dos trabalhadores, encontrando-se entre eles um enfermeiro recém formado, o que parece indicar ser o PSF um mercado de trabalho em expansão, com boa

${ }^{9}$ Aqui está se tomando a APS como o conjunto de ações desenvolvidas no primeiro nível de atendimento sob responsabilidade de instâncias municipais e que envolvem ações promocionais, preventivas, curativas, reabilitadoras dirigidas ao conjunto da população.

10 Segundo a legislação existente para o exercício de enfermagem, o Agente Comunitário de Saúde, não é uma categoria contemplada por lei. Este é o motivo por se optar neste estudo a terminologia de "trabalhadores ligados direta ou indiretamente à área de enfermagem", de modo a contemplar os Agentes Comunitários de Saúde. 
oportunidade para inserção de jovens trabalhadores.

O estudo de Araújo (1999) identifica que o perfil etário das equipes do PSF em Minas Gerais é conformado com a certa semelhança ao da presente investigação, ou seja, "são trabalhadores jovens, recém ingressos no mercado de trabalho podendo-se inferir que os mesmos estão em pleno vigor para o exercício das atividades laborais." (Araújo, 1999, p.65). Neste estudo, a autora chama atenção para o fato que $50 \%$ dos ACS naquele estado situavam-se na faixa etária de 18 a 25 anos, sendo que no presente estudo mais de $50 \%$ dos ACS situam-se na faixa dos 20 aos 30 anos, o que pode confirmar, para esta categoria ocupacional, a mesma afirmação do estudo de Araújo (1999), ou seja, é um grupo jovem que passa a estar inserido no mercado de trabalho em saúde.

Os trabalhadores ligados direta ou indiretamente à área de enfermagem são, majoritariamente, do sexo feminino representando $87,5 \%$ do total de trabalhadores, refletindo 0 que encontramos de forma geral nos recursos humanos de enfermagem. Do total de trabalhadores, $12,5 \%$ são do sexo masculino, sendo 1 auxiliar de enfermagem e 1 agente comunitário de saúde.

Ao se tomar o tempo médio de formação de enfermeiros e auxiliares de enfermagem dos municípios em estudo é de 9,7 anos, sendo que 3 deles ( 2 enfermeiros e 1 auxiliar de enfermagem) possuem mais que 10 anos de formação.

Observamos que dos profissionais, segundo formação ou capacitação específicas, que um enfermeiro possui curso de especialização, no entanto, este não é na área da saúde pública/ saúde coletiva, ou seja, nenhum enfermeiro possui especialização específica para atuar no Programa. Devemos salientar que não é necessário que médicos e enfermeiros tenham especialização para atuar no PSF, uma vez que o Programa prevê a atuação de profissionais com formação generalista.

Com relação à capacitação ${ }^{11}$ apenas 2 agentes comunitários de saúde não participaram de nenhum curso específico, pois passaram a fazer parte da equipe posteriormente à realização da mesma. A capacitação foi realizada na Universidade de São Paulo, numa proposta conjunta Escola de Enfermagem e Faculdade de Medicina de Ribeirão Preto - USP, DIR XVIII e Secretaria Municipal de Ribeirão Preto ${ }^{12}$, em novembro de 1998. A escolaridade dos agentes comunitários de saúde - ACS, apresenta uma diversidade de formação.

No Município A, todos os ACS possuem o nível superior de escolaridade, o que um lado pode vir a trazer vantagens, pois podem ser considerados mais esclarecidos e com maior capacidade de compreensão em determinadas situações. No entanto, nenhum apresenta formação na área da saúde. Por outro lado, isto pode ser um indicativo de que existe pouca oferta de emprego no município e os profissionais estão procurando trabalho nas diversas áreas mesmo que não seja a sua específica de formação e conhecimento, submetendo-se a salários menores do que teriam a possibilidade de ganhar.

[...] Prá dizer a verdade eu cheguei meio de susto, eu não sabia o que eu ia fazer, como eu te falei eu estava desempregada, prestei o concurso, passei e não sabia o que eu ia fazer eu vim assim de pára quedas, vim totalmente no escuro aí aqui nós começamos a estudar sobre o programa de saúde da família [...] (Agente comunitário de saúde 4)

${ }^{11}$ É importante diferenciar formação e capacitação. Por processo de formação compreendemse os processos formais de educação empreendidos na graduação, pós-graduação latu sensu ou stricto sensu, enquanto que os processos de capacitação correspondem àqueles de complementação em serviço e que adquirem o caráter de educação continuada.

${ }^{12} E$ importante ressaltar que, a partir de 1999, estas instituições juntamente com a faculdade de Medicina de São José do rio Preto, constituíram o Pólo Norte e Oeste de Formação Acadêmica e Capacitação em Saúde da Família. 
No Município B, 3 ACS estão fazendo o curso de auxiliar de enfermagem, pois acreditam que o mesmo é importante quando estão trabalhando na comunidade, como pode ser identificado na fala a seguir.

[...] exige, porque tem muitas coisas que tem que fazer, que tem que ter o curso de auxiliar [...] (Agente Comunitário de Saúde 5)

No Município C, O ACS possui o $1^{\circ} \mathrm{grau}$ completo e durante a entrevista expressou a vontade de fazer o curso de auxiliar de enfermagem:

[...] eu tinha vontade de ser auxiliar de enfermagem né, e espero um dia, eu vou fazer um curso, eu começo dia 22 de abril [...] (Agente Comunitário de Saúde 4)

O grau de escolaridade dos ACS também é reflexo da forma como foi realizada a seleção dos mesmos ao Programa, pois os municípios dispõem de autonomia neste processo de escolha. No Município A onde os 4 ACS têm o nível superior foi realizado concurso público razão pela qual, foram aprovados os que apresentavam maior nivel de escolaridade e, possivelmente, de conhecimentos gerais. No Município B os ACS já estavam trabalhando na área da saúde e foram "remanejadas", como veremos na tabela a seguir. No Município C o ACS foi indicado para preencher o cargo. Abaixo as falas representam os municípios $\mathbf{A}, \mathbf{B}$ e $\mathbf{C}$ respectivamente

[...] ai eu pedi as contas para me preparar para prestar concursos e ai saiu este concurso para montaro PSF ne, e eupresteio concurso que estava no jornal e eu vi que estava precisando e resolvi prestar e estou aqui. (Agente Comunitário de Saúde 1)

[...] eu trabalhava em um posto de saúde né, numa outra unidade e eles estavam iniciando este trabalho no Programa de Saúde da Familia aí. Então eu fui pedir para a Dra X. Insistimais com o Dr Y para ele deixar eu vir, então foi assim que eu consegui vir para cá [...] (Agente Comunitário de Saúde 5)

Ahh eu chegueiné através do prefeito, fui contratada né [...] (Agente Comunitário de Saúde 9)

QUADRO 1 - Distribuição dos ACS que atuam no PSF segundo a experiência anterior na área da saúde, para o período de janeiro a agosto de 1999. Ribeirão Preto, 2000.

\begin{tabular}{|c|c|c|c|}
\hline $\begin{array}{c}\text { Categoria } \\
\text { Ocupacional }\end{array}$ & APS * & Outro & Locaal* \\
\hline ACS 1 & - & 1 & Admin istração empresa \\
\hline ACS 2 & - & 1 & Administraçào pública \\
\hline ACS 3 & - & 1 & Nunca trabalhou \\
\hline ACS 4 & - & 1 & Educação rede pública \\
\hline ACS 5 & 1 & 1 & Atendente Posto Central Supermercado \\
\hline ACS 6 & 1 & - & Comércio EN \\
\hline ACS 7 & - & 1 & Atendente UBS \\
\hline ACS 8 & 1 & - & Funcionária consultório médico \\
\hline ACS 9 & - & 1 & \\
\hline Total & 3 & 7 & \\
\hline
\end{tabular}

\footnotetext{
* Estamos considerando APS o trabalho realizado na rede de atenção básica, não distinguindo as ações preventivas das curativas

** Um único trabalhador pode apresentar mais de uma atividade laboral anterior.
} 
Dados sobre a experiência anterior dos agentes comunitários de saúde podem ser observados no Quadro 1.

Dos 9 ACS, apenas 3 possuíam experiência anterior na área da saúde em Atenção Primária à Saúde, sendo todos do Município B. Estes eram atendentes de enfermagem e para não ser demitidos após a nova legislação do Conselho Federal de Enfermagem - COFEn foram deslocados para atuação no Programa. Como podemos verificarnesta fala:

[...] trabalhava há 8 anos lá na G. O. e vim para cá ... aí quando entrou o COREN, esse negócio de se não tiver o curso não pode ficar em certos lugares e eu estava na G.O., eu não tinha o curso, então eles não quiseram ... então eu fui pedir para a Doutora, insisti mais com o Doutor (Secretário Municipal da Saúde) para ele deixar eu vir, então foi assim que eu consegui vir para cá. (Agente Comunitário de Saúde 5)

Com relação aos agentes comunitários de saúde - ACS, tem-se colocado uma discussão pertinente, e que diz respeito ao fato de estar se abrindo espaço para novos atendentes de enfermagem, agora denominados de Agentes Comunitários de Saúde. Fato este, depois de um longo processo de discussão e luta para se colocar a necessidade de qualificação deste contingente de trabalhadores em eleva-los à outra categoria profissional. Os ACSs não dispondo de determinados conhecimentos necessários e específicos de saúde podem colocar em risco a saúde da população? Qual a qualidade deste serviço oferecido? Como orientam determinadas ações / situações sem ter conhecimento para tal?

Estas questões, já colocadas em avaliação anterior, principalmente, do Programa de Agentes Comunitários de Saúde ainda não foram suficientemente discutidas e mereceriam um espaço mais detalhado para análise. Minayo et al .(1990) em avaliação patrocinada pelo UNICEF, colocam que em Fortaleza já se constatavam diversas diferenças entre o que havia sido planejado e o que vinha sendo executado com relação às atividades dos agentes comunitários de saúde, pois estes realizavam ações específicas de enfermagem sem terem treinamento para tal. Além dos riscos aos quais a população ficou exposta, foi constatada a insatisfação dos agentes, quando os mesmos referiam que estas atividades eram desgastantes devido à falta de treinamento adequado para o seu desenvolvimento.

QUADRO 2 - Distribuição dos trabalhadores de enfermagem que atuam no PSF dos Municipios A, B e C, segundo a experiência anterior na área da saúde, para o período de janeiro a agosto de 1999. Ribeirão Preto, 2000.

\begin{tabular}{|c|c|c|c|}
\hline Profissional & $\mathbf{A P S}^{*}$ & Outro & Local** \\
\hline Enfermeiro 1 & $\operatorname{Sim}$ & $\operatorname{Sim}$ & $\begin{array}{l}\text { Hospital do câncer / Hospital Iniversitário Santa } \\
\text { Casa / Prefeitura Municipal / IBS do município }\end{array}$ \\
\hline Enfermeiro 2 & Sim & Sim & Clínica / IBS do município \\
\hline Enfermeiro 3 & $\operatorname{sim}$ & $\operatorname{Sim}$ & $\begin{array}{c}\text { Consultório Indústria Hospital e Maternidade } \\
\text { (JBS do municipio }\end{array}$ \\
\hline Auxiliar de Enfermagem 1 & Sim & - & I!BS sala de vacina - pré e pós consulta \\
\hline Auxiliar de Enfermagem 2 & - & $\operatorname{Sim}$ & $\begin{array}{c}\text { Hospital público / Santa Casa / Hospital privado } \\
\text { Hospital de Clínicas / I nidade de Emergência }\end{array}$ \\
\hline Auxiliar de Enfermagem 3 & Sim & - & Creche do município / I BBS do municipio \\
\hline Auxiliar de Enfermagem 4 & $\operatorname{Sim}$ & - & L'BSS sala de vacina \\
\hline Total & 6 & 4 & \\
\hline
\end{tabular}

\footnotetext{
* Estamos considerando APS o trabalho realizado na rede de atenção básica, não distinguindo as ações preventivas das curativas.

^* Um único trabalhador pode apresentar mais de uma atividade laboral anterior.
} 
Quanto aos enfermeiros, todos possuem experiências anteriores tanto em atenção primária à saúde - APS, como na área hospitalar. Os enfermeiros ENF2 e ENF3 já trabalhavam na rede básica do município, o que de certa forma, pode facilitar o conhecimento dos usuários, como podemos constatar nesta fala:

[...] acho que por eu morar no município e já saber também dos politicos, quem é de que partido, quem é de outro partido, uma família que não adianta bater em cima, que aquela família não aceita, não faz nada, eu já conhecia estes problemas aqui no município, então isso facilitou muito o trabalho e facilita até hoje. (Enfermeiro 2)

Dos auxiliares de enfermagem, 3 já trabalhavam na rede básica do município, não possuindo experiência anterior na área hospitalar. Apenas 1 possuía experiência na área hospitalar, nunca trabalhando na área de APS.

\section{O "perfil necessário" para o trabalho no PSF segundo os trabalhadores de enfermagem}

$\mathrm{Na}$ análise das falas dos trabalhadores ligados direta ou indiretamente à área de enfermagem que atuam no PSF nos municípios estudados, foi possível identificar algumas características que apontam para o que estamos aqui denominando de "perfil necessário" à atuação no Programa.

A análise será apresentada separada por categorias (enfermeiros, auxiliares de enfermagem e ACS), apesar de em alguns momentos apresentarem características comuns a todos os trabalhadores.

\section{- A percepção dos Enfermeiros}

Os enfermeiros têm a percepção de que para atuarem no PSF devem ter algumas características específicas, que se definem em duas direções:

\section{Ser comunicativo, ter bom relacionamento com a população, conhecer a população, gostar do seu trabalho e de trabalhos em grupo.}

Este perfil colocado, muito é em função da forma como o trabalho no Programa é configurado, pois os trabalhadores passam a ter contato íntimo com a população, conhecendo seus problemas / necessidades e, desta forma, distintos canais de comunicação são utilizados em todos momentos, tanto quando o profissional está na comunidade como quando está realizando trabalhos em grupo e na relação com a própria equipe.

Conhecer a população e ter bom relacionamento com esta é fundamental para a criação de vínculos e para a efetiva participação desta no Programa, como podemos verificar nas falas abaixo.

[...] fundamentalmente a gente tem que gostar de trabalhar com familias, ter muita força de vontade, ter bom relacionamento com a população [...] (Enfermeiro 3)

[...] a gente tem uma comunicação muito boa, a gente é um trabalho realmente em equipe $[\ldots]$ (Enfermeiro 2)

A segunda direção colocada pelos enfermeiros como característica essencial para atuarem no Programa é: 


\section{Ter dedicação ao mesmo, se envolver no trabalho, ter maior disponibilidade.}

A definição de uma microárea para a atuação no Programa, estabelece uma demanda de usuários e de atividades destinadas ao enfermeiro "mais delimitadas" que aquelas existentes em uma unidade básica de saúde - UBS, o que possibilita a este profissional se dedicar mais a algumas atividades que certamente não teria tempo numa unidade de saúde com uma demanda bastante geral e inespecífica.

Desta forma, o enfermeiro se envolve mais no seu trabalho e tem maior disponibilidade para atender as necessidades da população, mesmo quando a resolução desta necessidade não está diretamente ao seu alcance, ou seja, exigindo uma articulação, muitas vezes, com uma instância extra-institucional ou extra-setor saúde. As falas abaixo colocadas podem exemplificar o que foi colocado:

[...] então é um trabalho mais direcionado e muito mais dedicado, a gente cumpre o objetivo do programa né, e nem sempre isso é cumprido eu enfermeira do posto de saúde. [...] é completamente diferente, aqui a gente pode dedicar mais, porque no posto de saúde eu trabalho sozinha [...] (Enfermeiro 2)

[...] então a gente procura fazer o máximo, por exemplo, se tem alguém desempregado se é possivel arrumar alguma coisa para essa pessoa que está desempregada, se está passando fome a gente arruma cesta básica ... (Enfermeiro 3)

- A percepção dos Auxiliares de Enfermagem

Os auxiliares de enfermagem têm a percepção de que as características necessárias para a sua atuação no programa são voltadas para:

Ajudar a população, pois têm a concepção de que estão ajudando a população ao irem em suas casas, oferecendo alguns serviços como curativos e orientações, como pode ser verificado nestas falas:

[...] eu gosto muito de ajudar as pessoas, eu amo a minha profissão, eu gosto muito ... (Auxiliar de Enfermagem 3)

[...] eu acho que ajuda bastante, só de uma pessoa não sair de casa para ir lá fazer o curativo ... (Auxiliar de Enfermagem 4)

Ser dedicado e comunicativo, pois assim como os enfermeiros acreditam que a dedicação é fundamental para atuarem no programa.

... bom eu sou uma pessoa espontânea, procuro ser dedicada ...(Auxiliar de Enfermagem 2)

- Agentes Comunitários de Saúde

Os ACS trazem várias percepções acerca de como seria o perfil necessário para este trabalho no Programa, pois acreditam que devem ser: 


\section{Pessoas carinhosas, amorosas, amigas e confidentes da população}

Talvez este conjunto de qualidades expresso pelos trabalhadores, seja em função das atividades que estes ACS realizam, pois ao irem buscar a população não poderiam chegar sendo autoritários, ou numa atitude de imposição e prepotência. Para que se criem vínculos e confiança estas características colocadas talvez até sejam necessárias, devendo contudo ser considerado o significado disto numa relação de respeito e solidariedade no atendimento de necessidades de saúde.

Ou seja, há que se estabelecer relações de responsabilidade e compromisso, com a perspectiva de se possibilitar a emancipação e autonomia da população atendida, caso contrário estas qualidades voltam-se para uma relação de subordinação da população para com o trabalhador, sendo o mais enfática uma atitude assistencialista.

De qualquer maneira, é importante questionarmos se não estamos (com o PSF) despertando sentimentos importantes.Quando lidamos com seres humanos, muitas vezes até carentes de afetos, esta relação pode ser uma brecha importante para construirmos outras formas de atendimento às necessidades da população ${ }^{13}$.

[...] a gente cria uma confiança com a familia e com a pessoa e ela nos devolve carinho, a gente fica amiga, compreensão e a gente se sente importante com a família [...] e como eu posso te dizer a gente é amorosa com todos. [...] o que me levou a fazer realmente isso foi o carinho e a vontade de ajudar, a gente é um confidente fiel deles, o que eles tem o que eles não tem ... (Agente Comunitário de Saúde 9)

Eu acho que ele é diferente, acho que requer mais carinho, mais atenção, com o pessoal de modo geral, com os pacientes, porque você trabalhando dentro de uma unidade básica o pessoal eles vem até você na procura de alguma coisa, e nem sempre você tem tempo, aquela disposição para ficar conversando, agora já neste serviço é diferente, você vai atrás do paciente, você vai à procura dele, então é um elo mais forte entre o paciente e a unidade, acho que fica mais fácil de trabalhar, e o amor que você acaba sentindo pelo paciente como um todo. (Agente Comunitário de Saúde 8)

\section{Pessoas sempre prontas a ajudar, solidárias, que se envolvem no trabalho e com os problemas encontrados.}

Estas características apontadas pelos ACS em relação à forma como desenvolvem suas atividades direcionam-se à um cuidado voltado à caridade, ajuda e em alguns momentos assumindo inclusive um caráter religioso. "A subjetivação até aqui examinada convive num processo de trabalho que ainda transita de uma vocação divino caritativa ao processo tecnológico" (Campos, 1997).

... creio que o meu trabalho é muito útil e que eu posso ajudar muitas pessoas né, o contato com a pessoa me faz sentir muito bem, me faz sentir alguém e as

13 Neste sentido MERHY (1997) fala da criação de espaços intercessores, onde há sempre o estabelecimento de uma relação única entre trabalhador e usuário e a possibilidade de uma intervenção possivel para o encaminhamento das necessidades e sofrimentos apresentados pelo usuário. 
pessoas também gostam muito e vêem que é uma coisa boa. (Agente Comunitário de Saúde 9)

... o que mais incentiva a gente é isso, é a necessidade que eles têm de a gente tá ali com eles conversando, buscando o problema deles, ajudando também, sabe eles precisam de ajuda, então você sente útil quando uma pessoa necessita de você, então isso que faz a gente continuar, é essa carência deles. (Agente Comunitário de Saúde 6)

... eu sou uma pessoa assim que vai muito pelo lado da solidariedade acho que as pessoas têm que ter muito mais e está faltando hoje em dia então eu procuro ser uma pessoa solidária e transmitir isso para o meu trabalho. (Agente Comunitário de Saúde 3)

\section{Pessoas com grande disponibilidade e dedicação ao trabalho, que gostam de conversar, observar e lidar com pessoas}

Assim como para os enfermeiros e auxiliares de enfermagem, estas características se repetem, o que nos leva a afirmar que estas são características presentes a todos os trabalhadores que atuam nas equipes do PSF estudas.

...eu sou uma pessoa assim, gosta de conversar, gosto, gosto muito nossa eu adoro, por exemplo este contato com as pessoas, a saber e principalmente resolver. (Agente Comunitário de Saúde 9)

... o importante é isso, trabalhar sempre se dedicando ao máximo naquilo que faz ... (Agente Comunitário de Saúde 3)

... a gente precisa mesmo ser um bom observador, conversar bastante, assim para que as pessoas te falem o máximo dela, a rotina dela, da família para você conhecer um pouco né ... (Agente Comunitário de Saúde 3)

\section{ALGUMAS CONSIDERAÇÕES FINAIS}

O conjunto dos dados, embora aponte em alguns momentos para um perfil profissional que contempla uma prática de caráter assistencialista, encaminha ao mesmo tempo, a uma reflexão acerca de uma nova configuração da prática assistencial alicerçada na humanização e integralidade da assistência, assim como na construção da cidadania. Todas as características colocadas como presentes no perfil dos trabalhadores de enfermagem destas equipes do PSF, principalmente pelos ACS, encaminham para pensarmos nesta assistência mais humanizada e integral.

O desenvolvimento do trabalho no PSF parece encaminhar-se para uma maior possibilidade de proximidade com a comunidade, havendo reconhecimento e "personalização" do usuário que passa a ter um status diferenciado: de um usuário ele se transforma no usuário, com suas características, problemas, necessidades, inserido em uma família, num contexto sempre único e específico.

É importante que para finalizar retomemos o que Boff (1999, p.33) coloca em relação ao cuidado. "Cuidar é mais que um ato; é uma atitude. Portanto, abrange mais que um momento de atenção, de zelo e de desvelo. Representa uma atitude de ocupação, preocupação, de responsabilização e de envolvimento afetivo com o outro." 
Esta citação nos faz refletir que mesmo com os limites presentes e que apontam para um perfil assistencialista e religioso no que estamos denominando "perfil necessário", há uma potência real para que estas características possam colaborar para a mudança do modelo de assistência à saúde de modo mais responsável e humano.

\begin{abstract}
The purpose of this study is to characterize the demographic configuration of nursing personnel involved with the Family Health Program (FHP) in three municipalities of the state of São Paulo and analyse their perception about the expected professional profile in order to work in the FHP. Data was collected by means of semi-structured interviews and the software ETHNOGRAPH was used for initial data analysis, followed by thematic analysis. The themes identified by the subjects in their narratives point to the following "expected profile": there is a perception that workers must be communicative, dedicated, involved, sympathetic and tender. They should be easy to get along with, available and helpful to the population. Although, the results points to a professional profile which contemplates a "condescending" type of assistance, at the same time they point to a new type of health assistance based on humanization and integrality, as well as the construction of citizenship.
\end{abstract}

KEY WORDS: family health, public health nursing, nursing human resources

RESUMEN: El estudio objetiva caracterizar la configuración demográfica de los trabajadores de enfermería de los equipos del PSF de 3 municipios de São Paulo y analizar la percepción que tienen del perfil del profesional que va a actuar junto al PSF. Se utilizó como instrumento para colecctar datos la entrevista semiestructurada. Para la sistematización iniciall de los datos se usó el software ETHNOGRAPH y, posteriormente se hizo el análisis temático. Los temas apuntan a que es necesario tener un perfil, cual sea: deben ser comunicativos, dedicados, que se involucren en su oficio, solidarios, cariñosos, que tengan buen relacionamiento, disponibilidad y que ayuden a la población. El conjunto de datos, aunque apunte hacia un perfil que contempla una práctica de carácter asistencialista, al mismo tiempo, se encamina hacia una reflexión sobre una nueva configuración de la asistencia que tiene como cimientos la humanización e integralidad asistencial, así como la construcción de una ciudadanía.

PALABRAS CLAVE: salud de la familia, enfermería en salud pública, recursos humanos en enfermería

\title{
REFERÊNCIAS BIBLIOGRÁFICAS
}

ARAÚJO, Maria Rizoneide N. A saúde da família: construindo um novo paradigma de intervenção no processo saúde doença. 1999.141 p. Tese (Doutorado) - Escola de Enfermagem de São Paulo, Universidade de São Paulo, São Paulo

BOFF, Leonardo. Saber cuidar. Ética do humano - compaixão pela terra. Petrópolis: Vozes, 1999.

BRASIL. Ministério da Saúde. Saúde da Família: uma estratégia para reorientação do modelo assistencial. Brasília: Ministério da Saúde, 1998.

CAMPOS, Gastão W.S. et al. Planejanento sem normas. São Paulo: Hucitec, 1989.

CAMPOS, Gastão W.S. Subjetividades e administração de pessoal: considerações sobre modos de gerenciar trabalho em equipe de saúde. In: MERHY, Emersom E.; ONOCKO, Rosana. Agir em saúde - um desafio para o público. São Paulo: Hucitec, 1997.Cap.7, p.229-266

CORNETA, Vitória K.; MAIA, Carmen da C. A.; COSTA, Wildice G.A. A reorganização dos serviços de 
saúde no sistema único de saúde e a formação de recursos humanos. Saúde em Debate, Londrina/PR, n.51, p. 44-49, jun. 1996.

MERHY, Emerson E.; Onocko, Rosana. Agir em saúde - um desafio para o público. São Paulo: Hucitec, 1997.

MINAYO, Maria Cecília S. O desafio do conhecimento - metodologia de pesquisa social (qualitativa) em saúde. 2.ed. São Paulo: Hucitec, 1998.

MINAYO, Maria Cecilia S.; D'Elia, João Carlos; SVITONE, Ennio. Programa agentes comunitários de saúde do Ceará. Estudo de Caso UNICEF - Fundo das Nações Unidas para a Infância. Fortaleza, setembro de 1990. 